\title{
De SÚBDITOS A \\ CIUDADANOS: PRIMEROS \\ ENSAYOS EN CHIHUAHUA
}

\section{ALONSO DOMÍNGUEZ}

\section{RESUMEN}

$\amalg$ l surgimiento del sujeto social que ostenta los atributos, derechos, obligaciones y características del ciudadano ha sido un proceso largo y gradual. Algunas investigaciones soslayan lo anterior al tratar al ciudadano no como una construcción, a través del tiempo, del poder político y cultural de la nación, sino como algo que surge con toda su carga simbólica de una vez y para siempre con la constitución de Cádiz en 1812. Pero otra postura extrema afirma que la constitución gaditana no tuvo ningún efecto en los sujetos sociales. Algunas investigaciones minimizan, si no los resultados que se esperaban de la construcción de la ciudadanía, sí el impacto que en un primer momento tiene la Constitución de Cádiz y la propuesta de una nueva concepción del sujeto social y su inserción en la sociedad. Pensamos que faltan categorías analíticas que expliquen cómo surge el ciudadano y que puedan trazar puentes entre esas dos posiciones extremas. Con la Constitución de Cádiz el sujeto histórico ha sido en la práctica dotado del derecho de ejercer un sufragio, pero no ha interiorizado tal facultad de poder elegir a sus representantes y de situarse en un plano de mayor igualdad jurídica con los demás sujetos sociales, especialmente los más beneficiados y favorecidos del orden antiguo. Por eso no podemos hablar de un ciudadano, estamos ante un sujeto social que inicia un recorrido para 
interiorizar lo que el Estado pretende sea asimilado como tal, por lo tanto, en esta etapa inicial planteamos que no podemos hablar del ciudadano, sino del sujeto que está entre esa categoría y el súbdito, estamos ante un protociudadano.

Palabras clave: Ciudadano, protociudadano, constitución, Cádiz, elecciones

Especialmente, el análisis del presente trabajo se realiza partiendo de la villa de Chihuahua y su área de influencia electoral que abarcó lo que actualmente casi comprende el estado de Chihuahua. Por lo tanto, podemos definir una región, ya que aunque la villa formaba parte de la provincia de Nueva Vizcaya y su capital era Durango, Chihuahua ejercía mucha influencia y poder sobre la parte norte de la provincia, aún más que Durango. Chihuahua era el centro rector de tal región en sus dimensiones administrativas, políticas, sociales al tener una poderosa élite económica compuesta de mineros, hacendados y comerciantes.

Con base en la Constitución de Cádiz de 1812 se realizaron en la villa elecciones parroquiales, de partido y se mandarán los electores que le corresponden a Paso del Norte para participar en la elección final de diputados a Cortes y a la Diputación Provincial que se estableció en Durango. Asimismo, se llevó a cabo en la villa de Chihuahua la elección de ayuntamiento constitucional. Los procesos electorales mencionados nos dan la pauta para analizar al votante mostrándonos ya no un súbdito, porque ese elemento lo ha insertado en otro plano en el entramado social y político, pero tampoco en un ciudadano. Entonces, ¿cuáles fueron los alcances del ciudadano propuesto por Cádiz? pensamos que generó un protociudadano situado entre esas dos dimensiones sociales, lo cual a continuación analizamos.

Cronológicamente, el estudio comprende de marzo de 1812, cuando se emite la Constitución de Cádiz, a septiembre de 1814 cuando termina la elección de diputados a Cortes. Sin embargo, es importante retroceder cronológicamente y explorar más manifestaciones de expresiones de ciudadanía en el régimen Borbón. Chihuahua adquirió superioridad política sobre Durango debido a que en 1792 se le dio al comandante general de las Provincias 
Internas, establecido en la primera, autonomía sobre el virreinato de la Nueva España convirtiendo a la villa de Chihuahua en la virtual capital del septentrión.

Muchas de las investigaciones sobre la ciudadanía presuponen su creación de facto al asentarse por decreto constitucional. Las posiciones triunfalistas de la creación de la ciudadanía, como el mejor estado social y político del individuo, han dejado de lado no pocas de las observaciones realizadas por Antonio Annino (1999) y François-Xavier Guerra (1999). Algunas de esas posiciones ven en la ciudadanía un estado superior del individuo, hasta sacralizarlo. En el análisis histórico se debe ser cuidadoso para no asumir posiciones que nos lleven más a posturas ideológicas que a conclusiones académicas. Por otro lado, vemos que algunas de las posiciones de estos dos últimos teóricos minimizan, sino los resultados que se esperaban de la construcción de la ciudadanía, sí el impacto que en un primer momento tiene la Constitución de Cádiz y la propuesta de una nueva concepción del sujeto social y su inserción en la sociedad. Si bien Guerra ve que la voluntad autónoma en el ejercicio del voto fue algo inexistente y por ende el ciudadano, pensamos que en el momento de la aplicación de la Constitución de Cádiz no se buscaban esos alcances, el voto estaba enfocado a lograr mecanismos de representatividad y también creemos que abrir nuevos espacios de poder que subvirtieran el orden reinante. En la visión aristotélica, la voluntad autónoma no es parte esencial de la ciudadanía, sino su participación en la polis junto a una comunidad de ciudadanos.

Hay pues dos posiciones extremas en relación al surgimiento del ciudadano expresado en la constitución de Cádiz: una triunfalista y otra minimista. La posición de Hilda Sabato (1999) es relativista al señalar que los alcances de la ciudadanía fueron variables. En ciertos puntos su posición es moderada en relación a triunfalistas y minimistas, lo cual creemos es más adecuado al momento de explicar la génesis de la ciudadanía. Sin embargo, pensamos que faltan categorías analíticas que explique esa génesis y que puedan trazar puentes entre las dos posiciones extremas. El sujeto histórico ha sido en la práctica dotado del derecho y obligación de ejercer un sufragio que es en la práctica una expre- 
sión ciudadana, pero ese sujeto no ha interiorizado tal facultad de poder elegir a sus representantes y de situarse en un plano de igualdad jurídica con los demás sujetos sociales, especialmente los más beneficiados y favorecidos del orden antiguo. En ese sentido, no podemos hablar de un ciudadano, estamos ante un sujeto social que inicia un recorrido para alcanzar ese estado, por lo tanto, en esta etapa inicial estamos hablando de un protociudadano: sujeto que está entre el súbdito pero no ha llegado a ciudadano.

La ciudadanía se ha convertido en un concepto laxo y acuoso, difícil de manejar por las múltiples concepciones que se han desarrollado del término. En la teoría aristotélica clásica la ciudadanía no se define de manera abstracta sino a partir de la acción (praxis). La participación efectiva en la vida pública, en las funciones de gobierno, en la asamblea, en los tribunales, en la administración pública es ser ciudadano. Era ciudadano porque participaba en la polis; no porque primero tuviera derechos o jurara una lealtad abstracta, sino como parte del actuar en la comunidad política con los otros ciudadanos (Gallegos, 2011, p. 69).

Marshall desarrolla su tipología conceptual a partir del desarrollo histórico de la ciudadanía en los distintos tipos de derecho: civil, político y social. El primero se compone de los derechos que hacen valer la libertad individual: libertad de la persona, de expresión, de pensamiento, religión, derecho a la propiedad y a establecer contratos válidos y derecho a la justicia. El segundo comprende el derecho a participar en el ejercicio del poder político como un miembro de un cuerpo investido de autoridad política o como elector de sus miembros. El social se refiere al derecho a la seguridad y a un mínimo de bienestar económico, compartir la herencia social y vivir la vida de un ser civilizado conforme a la sociedad (1998, pp. 22-23). Arroyo prefiere estudiarla desde los aspectos que requieren el ensamble de diversos ámbitos en estrecha relación necesarios para la "fabricación" de ciudadanos: doctrina, descenso constitucional y aprensión social (2011, p. 525).

Para Antonio Annino, el liberalismo gaditano teorizó la superación del contractualismo del Antiguo Régimen por medio de la representación, pero no abolió la monarquía, así el vecino de Cádiz se volvió ciudadano, pero también conservó su condición de 
súbdito. La Constitución de Cádiz describió un conjunto de nuevos derechos pero dejó en vigor las Leyes de Indias que no contrariaban los nuevos principios. En virtud de ello, la frontera entre el ciudadano moderno y el súbdito antiguo fue muy débil, si no que inexistente (Annino, 1999, p. 75). En el esquema aristotélico se resalta la efectiva vinculación entre el ciudadano y ciudad. Se era ciudadano de la ciudad y no en o para la ciudad. Sin ciudadano no podía haber ciudad (Gallegos, 2011, p. 69). Para Guerra la diferencia entre vecino y ciudadano es pertinente en el plano de los principios, pero él se cuestiona si la ruptura con la antigua concepción era un hecho o un ideal en competencia con otras concepciones más extendidas y tradicionales, esa era la confusión de aquellos que habitaban en aldea, pueblo o villa pero no en ciudad, entonces cómo podían ser ciudadanos (Guerra, 1999, pp. 40-41). Lo anterior nos recuerda el agudo conflicto entre la villa de Chihuahua y la ciudad Durango por ser la sede de los poderes e instituciones gubernamentales ya sea del antiguo o el nuevo régimen. Los de Durango argumentaban superioridad precisamente por tener título de ciudad, por tener más población, más equipamiento urbano e institucional y más poder económico. Si Durango era la capital de la provincia los de Chihuahua decían ser la capital de todas las Provincias Internas por residir allí su máxima autoridad, el comandante general. Peleaban y gestionaban que se les diera el estatus de ciudad para poder competir mejor con Durango. Pero al darles la Constitución de Cádiz, el derecho a ser ciudadanos no sintieron que la villa era una ciudad, cómo era posible si no había un título real. Podía haber ciudadanos sin ciudad, (Domínguez, 2013, pp. 50, 257, 345, 348). La legislación de Indias era estricta en ese sentido, marcaba que por ningún motivo los virreyes, audiencias o cualquier otro ministro de las Indias por superiores que fueran dieran títulos de ciudades o villas a cualquier pueblo (Recopilación de Leyes de los Reynos de las Indias. Libro IV, título VII, ley VI.)

Para Hilda Sabato, la construcción de la ciudadanía no se debe ver como algo que de facto suple al súbdito o al vecino. En el libro que esta autora coordinó: Ciudadanía política y formación de las naciones. Perspectivas históricas de América Latina, encuentra que los alcances y los límites de la ciudadanía definidos a partir de 
la extensión de los derechos políticos y en concreto del derecho al voto fueron muy variables. Lejos de generarse una ampliación gradual de ese derecho a partir de una ciudadanía restringida por los requerimientos de propiedad, en buena parte de Iberoamérica la independencia introdujo un concepto relativamente amplio de ciudadano tendiente a incluir a todos los varones adultos, libres, no dependientes más cercano al citoyen de la Francia revolucionaria que al ciudadano propietario de Locke. En ese sentido, Sabato argumenta que en Iberoamérica se produjo una superposición y sucesión de formas y mecanismos de representación diversos. En ese marco se inscriben los procesos electorales considerados pieza clave en la transformación de los sistemas de representación. El problema que surge es: quiénes eran representados y quiénes podían elegir y ser elegidos (Sabato, 1999, pp. 18-19). En esa línea, Sabato pregunta cuál fue el papel de las elecciones en el plano de las relaciones entre sociedad civil y sistema político y de la conformación efectiva de una ciudadanía. Responde que no hay una respuesta única, (Sabato, 1999, p. 23).

El concepto de ciudadanía de Cádiz se encuentra ligado al de soberanía y representación política. En particular en lo que hace a los territorios ultramarinos los ciudadanos debían realizar elecciones para enviar representantes a España. No está exento de carga ideológica, conlleva como se le quiera analizar, inclusión o exclusión. Se expresa el reconocimiento de igualdad política entre la península y los territorios de ultramar, pero hay una categórica diferenciación entre el ser español y ciudadano. El no considerar a todos los habitantes peninsulares y de América como iguales y distinción que se seguía haciendo de los españoles con el total del conjunto trajo a colación la distinción entre los derechos civiles y los políticos. Los primeros debían reconocerse a todos los españoles y los segundos únicamente a aquellos capacitados intelectualmente para participar en la toma de decisiones (Hernández, 2012, pp. 299-301).

Para Sánchez, la Constitución de Cádiz proponía una definición más incluyente de pueblo político basado en la ciudadanía. En adelante el referente era la sociedad y no la ciudad, pero como individuos portadores, tanto de derechos civiles como de dere- 
chos políticos. Era un significado mucho más amplio que el de vecino aunque seguía demandando la pertenencia a una comunidad-territorio para que estos derechos fueran reconocidos, (Sánchez, 2009). Para Alicia Hernández, la ciudadanía fue un concepto revolucionario porque su operación permitía superar las tensiones entre vecinos y avecindados, migrantes y jornaleros, extendiéndose los derechos políticos a todo hombre con modo honesto de vivir independientemente de su connotación étnica y rango social. Para Hernández, el ciudadano se levantaba como el único titular de la soberanía, la cual no podía ser delegada ni transferida a un soberano y debía ejercerse por medio de la elección de sus representantes (Hernández, 1993, p. 32).

\section{¿EL GERMEN DEL CIUDADANO EN EL RÉGIMEN BORBÓN?}

Horst Pietschmann aventura que el aspecto del ciudadano era manejado por los borbones al grado de tener los visos de un programa. Pone el ejemplo del virrey Bernardo de Gálvez, el cual ante los problemas de una grave crisis de hambre, en la ciudad de México, convocó a una "junta de ciudadanos" para encontrar soluciones. Se debe haber visto con extrañamiento el uso del término, pero sobre todo significaba excluir a las instituciones con las que usualmente se trataba este tipo de problemas como el Real Acuerdo, el cabildo o la junta de vecinos notables. Asimismo en ciertas figuras y expresiones usados por los borbones se vislumbraba al hombre concebido como un individuo y al Estado desarrollando políticas para brindarle la posibilidad de desarrollarse. Para Pietschmann en el fondo ya estaban allí los principios del Estado liberal burgués, (1996, pp. 34-35).

Las reformas borbónicas iban encaminadas a individualizar la sociedad septentrional y con ello la Nueva Vizcaya, en ese sentido podría decirse que también a ciudadanizarla. Al tratar de desarticular la sociedad monástica para crear la sociedad civil; al tratar de repartir las tierras de las misiones y pueblos en propiedad privada a los indios y los posteriores esfuerzo para que interiorice el sentido de la propiedad privada; al crear colonias militares bajo régimen de propiedad 
de la tierra sustentadas en los jefes de familia y no en grupos corporativos; al exigir que se distingan esas propiedades con los de otros colonos poniendo en sus límites árboles o mejor con cercas y bardas. Pero para el régimen monárquico la naturaleza de ciudadano no significaba una ruptura con su condición de súbdito. Por el contrario, era tener sujetos más eficientes y leales en el ejercicio del vasallaje. Por ejemplo, que los indios reconocieran al monarca y no pusieran su lealtad en la misión o en el grupo étnico (Domínguez, 2013, p. 327).

El auditor de guerra y abogado de la comandancia general, con sede en la villa de Chihuahua, Mariano Herrera al defender a Diego Pérez, administrador de alcabalas del Real del Rosario, acusado de usar expresiones verbales en contra del rey, utilizó el concepto de ciudadanía en su defensa. Aseguró que existían tres clases de libertad: la natural, la política y la civil, siendo la última la que poseía el hombre como ciudadano y era garante de su tranquilidad (González, 1993, pp. 26-27). Lo más interesante es que utilizaba el término para defensa jurídica antes de la promulgación de la constitución de Cádiz.

\section{LAS ELECCIONES DE DIPUTADOS A CORTES Y A LA DIPUTACIÓN PROVINCIAL}

Las elecciones en las Provincias Internas de Occidente se realizaron bajo el antecedente y el contexto de diferentes elementos disgregadores: a) la insurgencia en el virreinato, a la cual el ejército de Tierra Adentro había impedido con gran efectividad que ingresara a su jurisdicción; b) el conflicto entre el ayuntamiento de Chihuahua y Durango por ser la sede donde se instalara la Junta Preparatoria; y c) una conspiración descubierta en 1811 en las que participaron prominentes personajes de la comandancia general de las Provincias Internas, su auditor de guerra, de origen peruano, Mariano Herrera, el comandante de una pequeña escuela militar adscrita a la comandancia, el teniente Juan Pedro Walker, y el regidor alguacil mayor del ayuntamiento de Chihuahua y capitán de infantería de una de las compañías urbanas de milicias Salvador Porras. Fueron encarcelados pero pronto libera- 
dos, Porras perdió sus cargos y fue multado. En cambio Herrera pudo regresar a su puesto y a Walker se le condenó al destierro. Eran sentencias menores para la magnitud de los hechos, pero las relaciones sociales al interior de los grupos de poder en la villa de Chihuahua quedaron fracturadas (Domínguez, 2013, pp. 221-228, 266, 285-287). La aprehensión y proceso de sentencia generó gran enemistad, principalmente entre el auditor de guerra Mariano Herrera y el alcalde de la villa de Chihuahua en 1811, el peninsular Pedro de Valois y por extensión con el yerno de este Pedro Ignacio de Irigoyen. Lo anterior perfilará el enfrentamiento entre españoles y criollos teniendo los últimos como principal intelectual y líder a Mariano Herrera. Dichas rivalidades vinculadas a los procesos electorales desembocarán en otra conspiración en 1814 teniendo como principales protagonistas al propio Herrera, José Feliz Trespalacios, Juan Pablo Caballero y José María Arrieta.

Ante los avances de las tropas de Napoleón en diciembre de 1808 la Junta Central se refugia en Sevilla. En esta etapa sus miembros se dan cuenta de la importancia de integrar representantes americanos. Por un lado, necesitaban continuar con la recepción de recursos económicos y había el temor de la independencia de los territorios. Por lo tanto, la Junta Central decide convocar a elecciones en los reinos americanos. Posteriormente se proclamó la igualdad de estatus entre la metrópoli y sus dominios. El decreto de 22 de enero de 1809 estableció que las posesiones españolas no eran colonias o factorías sino reinos dentro de la monarquía española, por lo que se convocó a los virreinatos y capitanías generales a enviar diputados. Una serie de dificultades y tardanzas en la celebración de los comicios impidieron que los diputados electos se incorporaran a la Junta Central. El proceso implicó dos niveles, primero se hacía una votación dentro de los ayuntamientos de las principales ciudades para que quedaran tres personas y de entre ellas por sorteo salía el diputado (Cruzado, 2013, pp. 35-37).

Los acontecimientos militares determinaron la salida de la Junta Central de Sevilla a Cádiz donde se disolvió, sucediéndola después la Regencia. Su último decreto, de 29 de enero de 1810, estableció las condiciones para elegir representantes a la asamblea. 
Para este proceso se determinó que debía haber un diputado por cabeza de partido de provincia, lo cual resultó muy vago y provocó distintas interpretaciones en los territorios americanos. El 14 de febrero de 1810 la Regencia expidió una proclama en la que apremiaba a la elección de representantes americanos a los que ahora se les daba el título de "hombres libres" y la responsabilidad de los destinos de América a través de la elección de representantes para reunirse en septiembre de ese año (Cruzado, 2013, pp. 38-39). El proceso, aunque más limitado, era muy parecido al anterior, solo para los ayuntamientos de capital cabeza de partido. El concejo municipal escogía a tres personas que se distinguieran por su inteligencia, integridad y cultura. El diputado también era sorteado al escribirse los nombres de los tres en papeletas separadas y se retiraba de la urna una de ellas (Cruzado, 2013, p. 42).

En las Provincias Internas la elección de diputados a Cortes generó un gran número de interrogantes al no darse los nombres de las capitales de las provincias que tendrían derecho de elegir diputado a Cortes, lo que provocó confusión en las autoridades. No era algo sencillo, ya que había un complicado traslape de jurisdicciones provinciales, militares, eclesiásticas, intendenciales y judiciales que generaba el cuestionamiento de cuáles debían considerarse capitales provinciales (Domínguez, 2013, p. 278).

Los diputados americanos se empeñaron en que, tanto indígenas como castas, tuvieran derecho a la ciudadanía, consiguiéndose solo para los primeros, para los segundos no se pudo lograr siquiera que contaran como población para ser representados. El 19 de marzo de 1812 los parlamentarios de Cádiz promulgaron la Constitución de la Monarquía Española (Cruzado, 2013, p. 48).

Se excluyó a las castas de la ciudadanía para que "la base para la representación" de los diputados peninsulares fuera mayor que la de los de América. Se calculaba que América española tenía una población de entre 15 a 16 millones de habitantes, mientras que la de España no rebasaba los 10 millones. Pero no contando a las castas como base electoral, la superioridad numérica peninsular sobre América sería clara (Tateishi, 2008, p. 11).

El 23 de mayo de 1812 el Consejo de Regencia expidió el decreto que conllevaba la Instrucción conforme a la cual deberán celebrarse 
en las Provincias de Ultramar las elecciones de Diputados de Cortes para las ordinarias del año próximo de 1813. Para la organización de estas elecciones se previno la creación de la Junta Preparatoria en las provincias, la cual también debía organizar las elecciones de diputados provinciales. Como vimos la Constitución de Cádiz excluyó a negros y castas del derecho al voto y solo permitió la participación y representación para lo que se consideraron ciudadanos, además mayores de veinticinco años y solo para varones. La elección tanto de diputados a Cortes como provinciales se llevaba a cabo mediante un régimen de cuatro elecciones sucesivas: de compromisarios, de parroquia, de partido y de provincia (Guerra, 1999, p. 57). Las de compromisarios y de parroquia se llevaron a cabo con los ciudadanos avecindados y residentes en el territorio parroquial; elegidos los electores de parroquia debían reunirse en la cabecera de partido para a su vez elegir a los electores que reunidos en la capital de provincia votarían por los diputados a Cortes y provinciales. (Gortari, 2012, pp. 352, 355). Para estas elecciones se formó una jurisdicción electoral con la parte norte de la Nueva Vizcaya, lo que es el actual estado de Chihuahua, junto con Nuevo México para completar los setenta mil habitantes que se necesitaban para elegir un diputado a Cortes. La elección provincial se llevaría a cabo en Paso del Norte donde además se elegirían dos diputados provinciales y un suplente.

Por las Provincias Internas fueron electos los eclesiásticos Manuel María Moreno por Sonora-Sinaloa, Juan José Güereña por Nueva Vizcaya y Miguel Ramos Arizpe por Coahuila (Guzmán, 1949, pp. 7-9). Por Nuevo México el empresario Pedro Bautista Pino, pero como tuvo que recorrer una gran distancia no llegó a Cádiz hasta agosto de 1812, cuando ya la Constitución había sido publicada. Texas no pudo mandar un representante ya que según un funcionario local no había candidato aceptable y de haberse tenido no se hubieran podido sufragar los gastos. El virrey determinó que las Californias, en cuanto a que en ese momento dependía de él, no tenía derecho a la representación (Weber, 1988, pp. 47-48).

El decreto compuesto de diecisiete artículos señalaba que la Junta Preparatoria se debía integrar por el jefe superior, el arzobispo u obispo, intendente donde lo hubiera, del alcalde más 
antiguo, del regidor decano, del síndico procurador general y de dos hombres "buenos" de la provincia. En virtud de lo anterior y por ser Durango la capital de la Nueva Vizcaya se instaló allí con el gobernador-intendente interino Ángel Pinilla fungiendo como presidente de tal órgano. Por lo tanto, de Durango partieron todas las instrucciones y ordenamientos para realizar las elecciones en todos los pueblos de las Provincias Internas de Occidente. La Junta Preparatoria no debía intervenir en los tres niveles de juntas electorales y su función cesaba completamente al quedar constituida la Diputación Provincial, que quedaría igualmente instalada en Durango (Domínguez, 2013, p. 285).

El ser votante es una característica connatural del ciudadano surgido del sistema electoral gaditano. En relación a su carácter de votante Annino afirma que estructuraba en realidad una jerarquía de diferentes ciudadanías en relación a los requisitos y derechos. La construcción de la nueva representación se consumaba en las juntas provinciales, únicas que podían dar la soberanía a las Cortes por medio del voto (Annino, 1999, p. 69). Guerra implica que el ser votante no generaba de facto al ciudadano ya que un voto libre, en el supuesto de que así fuera, no era necesariamente producto de la voluntad autónoma. El ciudadano se encontraba inmerso en una red de vínculos sociales muy densos y por eso se manifestaba, a través de su voto, ante todo como miembro de un grupo, ya fuera el familiar, social o territorial. Por otra parte, Guerra pone de relieve el lenguaje usado para designar el acto mismo de la elección, como "nombramiento" o "nombrar" y no elegir, lo cual es significativo del universo mental de la época. Para él no se trataba de resolver por el voto una competencia entre diferentes candidatos, sino de seleccionar a los más aptos. Cuando se convoca a la elección de diputados americanos a la Junta Central se pedía que los mismos tuvieran ciertas características: "individuos de notoria probidad, talento e instrucción, exentos de toda nota que pueda menoscabar la opinión pública".

Entonces, se trata de seleccionar en función de dignidad, cualidades intelectuales y morales reconocidas socialmente. Abunda Guerra que el análisis de los procesos de nulidad de elecciones muestra que ningún caso revela una confrontación entre hom- 
bres con concepciones políticas diferentes, si existen no son visibles. Tampoco los grupos revelan conflictos definidos por criterios puramente económicos. Las divisiones electorales no remiten a individuos ni a la rivalidad por tendencias políticas o intereses diversos, sino a conflictos entre actores colectivos de una sociedad premoderna. La acción de los grupos no está enfocada a captar el voto de los ciudadanos mediante la exposición pública de sus ideas o proyectos, su accionar obedece a las formas de los viejos actores colectivos (Guerra, 1999, pp. 52-56).

\section{LA COMPLICADA ELECCIÓN DEL AYUNTAMIENTO CONSTITUCIONAL DE CHIHUAHUA}

En cuanto a los ayuntamientos constitucionales Moisés Guzmán plantea que los estudios realizados han tratado principalmente las siguientes temáticas: el grado de aceptación que tuvo la Constitución; las prácticas electorales que se desarrollaron al interior de los ayuntamientos como de los pueblos; el proceso e implicaciones de la conversión de los vasallos a ciudadanos y el fortalecimiento de los pueblos indios de acuerdo a los postulados de la Constitución. Recientemente, nuevos trabajos han derivado de esos planteamientos iniciales abordando su estudio desde el aspecto regional y con mayor profundidad analítica. Sin embargo, para lo que fueron las Provincias Internas hay una carencia notable (Guzmán, 2009, pp. 7-14). Antonio Annino planteó que la introducción del voto en los pueblos creó una revolución territorial y el quiebre del espacio político (1995).

Entre 1812 y 1814 se formaron en la Nueva España novecientos ayuntamientos, catorce en Nueva Vizcaya, cuando anteriormente solo apenas excedían las tres decenas, (Hernández, 1993, pp. 24-25). Antonio Escobar expresa que en el caso de la Huasteca hidalguense, potosina y veracruzana, los ayuntamientos pretendieron sustituir las formas organizativas indígenas para acceder a los recursos materiales y monetarios que necesitaban las tropas realistas (2009, pp. 66-67). Otros investigadores han señalado la dificultad de fijar categorías de análisis en su estudio dada la gran diversidad de su composición: étnica, ubicación geográfica, 
categoría política de la población y principales actividades económicas (Talavera, 2009, p. 82).

También el 23 de mayo de 1812 el Consejo de Regencia expidió el decreto para la Formación de los Ayuntamientos Constitucionales fijando que los pueblos que no pasaran de 200 vecinos podrían tener un alcalde, dos regidores y un procurador; aquellos entre 200 y 500, un alcalde, cuatro regidores y un procurador; entre quinientos y mil, dos alcaldes, seis regidores, y un procurador; entre mil a cuatro mil, dos alcaldes, ocho regidores y dos procuradores y en los de mayor vecindario aumentaría el número de regidores a doce. Los vecinos que estuvieran en ejercicio de sus derechos de ciudadanos elegirían nueve electores en los pueblos que no llegaran a mil, dieciséis en los pueblos que pasando de mil no pasaran de cinco mil y veinticinco en los pueblos de más de esta última cifra. Acto seguido, esos electores elegían a los miembros del ayuntamiento. Competía al jefe político presidir la junta de electores, en su defecto el alcalde o el regidor más antiguo. Se reafirmaba lo señalado por la Constitución en cuanto a que cesaban los puestos perpetuos de ayuntamiento.

El decreto compuesto de trece artículos, fijó que habiendo la junta ciudadana elegido a los electores, posteriormente se reuniría la junta de electores que la presidiría el jefe político, si lo hubiere, y si no, por el más antiguo de los alcaldes, y en defecto de estos por el regidor más antiguo. Pero el gobernador-intendente, radicado en Durango, nombró en Chihuahua a Francisco del Valle subdelegado real, por lo tanto, sería el encargado de dar a conocer las convocatorias y organizar en la Villa las elecciones, tanto de ayuntamiento constitucional como las de diputados a Cortes y provinciales en sus niveles de parroquia y de partido dado que Chihuahua era cabecera de partido.

El 3 de diciembre de 1813 ya estaba formado el padrón del vecindario de la Villa y el 5 de ese mes quedó instalada la junta de ciudadanos para elegir a pluralidad de votos a los miembros del cabildo que, según la población a la villa de Chihuahua, le correspondían doce puestos. Primero debían elegirse a los diecisiete electores, los cuales compondrían la correspondiente junta electoral y de entre los cuales saldrían los miembros del ayunta- 
miento. La instrucción de Formación de los ayuntamientos Constitucionales fijaba que la junta de electores la presidiría el jefe político, el cual junto con los electores debían reunirse para "conferenciar sobre las personas que puedan convenir para el mejor gobierno del pueblo; y no podrá disolverse sin haber concluido la elección". Aunque de un número reducido de posibilidades, entonces el proceso final era una designación por consenso.

El 8 de diciembre se llevó a cabo la elección del ayuntamiento constitucional presidiendo la junta electoral (véase el cuadro 1) el subdelegado en la villa de Chihuahua Francisco del Valle. Francisco José de Jáuregui y Pedro de Valois quedaron como alcalde primero y segundo respectivamente; José Feliz Trespalacios como regidor. Herrera quedó entre los electores pero no podía quedar dentro del ayuntamiento, dado que en la Constitución se prohibió a los "servidores públicos" nombrados por el rey ocupar cargos de cabildo y él era auditor de guerra. La aseveración, según el acta, de del Valle de que la elección se había desarrollado en paz y orden estaba muy alejada de la realidad. En la conferencia donde los electores designaban a los miembros del cabildo Herrera impugnó a Valois alegando que era comandante de milicias (АНMCH, Fondo: Colonia, Sección: Gobierno, Caja 48, Exp. 35).

Pero otro problema se presentó cuando al revisar el gobernador-intendente interino, Ángel Pinilla, radicado en Durango, la documentación electoral se dio cuenta que no se había nombrado por la junta de ciudadanos un secretario como lo prevenía la reglamentación. Había actuado como tal José María Ponce de León secretario interino del antiguo cabildo y Pinilla no validó la elección. Los integrantes del antiguo ayuntamiento se reunieron para discutir la situación. Acordaron pedir que se pasara por alto la omisión argumentando que una nueva elección traería debates y consecuencias en contra de la paz, sosiego y señalaron a del Valle como culpable dado que las elecciones habían estado bajo su cargo (AHмCH, Fondo: Colonia, Sección: Gobierno, Caja 48, Exp. 32).

Del Valle consultó a Herrera sobre la situación, el cual contundente dijo que la elección se había llevado a cabo sin acatar lo prescrito en la ley y no podía haber excepción del caso. Herrera estaba a favor de repetir la elección para posicionar mejor a su 
grupo antiespañol. Pinilla ordenó a del Valle que convocara a la junta ciudadana y realizara nuevamente el proceso electoral. En voz del antiguo ayuntamiento, el alcalde Juan José Ruiz de Bustamante amenazante le comunicó a del Valle que no llevarían a cabo otro proceso electoral. Sobre tal decisión, Herrera afirmó a del Valle que Ruiz no tenía facultades sobre el proceso electoral y solo a él le competía hacer la convocatoria y demás disposiciones para llevar a cabo la elección. Lo conminó a que inmediatamente convocara a la junta ciudadana, ya que el pueblo estaba a la expectación y con el "deseo de tener Ayuntamiento Constitucional y no aristocracia” (AHMCH, Fondo: Colonia, Sección: Gobierno, Caja 49, Exp. 50.). El mismo comandante general sancionó el asunto ordenando se repitieran las elecciones (AHMCH, Fondo: Colonia, Sección: Gobierno, Caja 48, Exp. 32).

A continuación, el grupo Herrera-Trespalacios fijó como objetivo primordial apartar a Valois de la alcaldía y llevar a Trespalacios a alcalde primero y como segundo a Jáuregui o Zubía. Asimismo hacer regidor a salvador Porras. El 16 de enero de 1814 se repitió la elección y la junta ciudadana nombró secretario a Eugenio Vizoso. Entre los diecisiete electores quedaron Herrera, Trespalacios y se estrenaban en tal responsabilidad sus adeptos Salvador Porras y Sabino Diego de la Pedrueza. Para lograr su objetivo el grupo se había movilizado y el día de la elección Herrera mandó a su secretario Juan Pablo Caballero una lista que se repartió en los contornos de la villa (AGN, Infidencias 126, f. 5v.). El grupo logró su cometido quedando como alcaldes primero y segundo Jáuregui y Trespalacios respectivamente y agregándose Porras y Pedrueza al cabildo, pero las elecciones se volvieron a anular. El nuevo gobernador-intendente interino Juan José Zambrano argumentó que Porras estaba privado de sus derechos de ciudadano, por haber conspirado en 1811, lo excluyó del cabildo y dio posesión a los demás. Pero el comandante general Bonavía declaró nula la elección. Los miembros del antiguo ayuntamiento en esta ocasión no hicieron alharaca, dado que si se repetía el proceso podrían debilitar al grupo Herrera-Trespalacios (АнмCH, Fondo: Colonia, Sección: Gobierno, Caja 49, Exp. 51). 
Antes de que se declarara nula la segunda elección de ayuntamiento constitucional se realizaron las de diputados a Cortes y provinciales. El 23 de enero de 1814 se llevó a cabo el proceso iniciando con el nombramiento de los dos escrutadores y del secretario: párroco Mateo Sánchez Álvarez, Eugenio Vizoso, Julián Zubía respectivamente y la elección de los treinta y un compromisarios que le correspondía a la villa. Para diputados a Cortes y provinciales la base de la elección seguía siendo el territorio parroquial, el cual comprendía un padrón de mil seiscientos votantes por lo que le correspondían ocho electores parroquiales. En este proceso, Trespalacios luchaba por quedar como diputado a Cortes o provincial pero el grupo sufrió duro revés, él y Porras lograron quedar entre los compromisarios pero no como electores. Entre los electores quedaron los que bien había llamado Herrera aristócratas: Simón de Ochoa, Pedro Ignacio de Irigoyen, Mateo Sánchez Álvarez, Francisco José de Jáuregui, Rafael Zubía, Francisco Arregui, Juan José de Arenas, y Eugenio Vizoso (AHмcH, Fondo: Colonia, Sección: Gobierno, Caja 49, Exp. 48.). Después de realizarse las elecciones en su nivel de partido, el 30 de enero de 1814, los doce electores de todos los partidos de la jurisdicción electoral se reunieron en Paso del Norte para la elección de diputados a Cortes y provinciales. Se realizaron entre el 11 y 14 de marzo de 1814 y quedó como diputado a Cortes Francisco José de Jáuregui (АнмсH, Fondo: Colonia, Sección: Gobierno, Caja 49, Exp. 48), Simón de Ochoa como suplente de Jáuregui y se eligieron para diputados provinciales a Juan Rafael Ortiz de Santa Fe, Nuevo México y Mateo Sánchez Álvarez de la villa de Chihuahua (Vaquera, 1974, en Orozco, 2007, p. 73). Trespalacios buscaba como influir ya que no se había conformado con los procesos previos a la elección y envió a su cuñado Juan García y al secretario de la comandancia general Juan Pablo Caballero pero nada se pudo hacer (AGN, Infidencias 126, f. 5-5v.).

La tercera elección de ayuntamiento constitucional se tornó muy conflictiva más por las anulaciones que desde Durango se había hecho de los procesos pasados y se empezó a temer que se suscitaran disturbios. Se convocó para el 17 de marzo de 1814 para la elección, pero los miembros del cabildo antiguo asumieron una 
posición dura y alegaron que en cuanto fuera electo el cabildo se debía poner en posesión sin que tuviera que ser validado y si había algún motivo de nulidad solo la autoridad competente debía decidir sobre el particular. También autorizaban a los electoreros a defender los "derechos del pueblo." El 2 de abril se llevaron a cabo las elecciones, como Jáuregui había quedado como diputado a Cortes y tenía que trasladarse a España ya no podía ser elegido alcalde, entonces fue electo Valois alcalde primero y Trespalacios fue desplazado a regidor.

Parecía que sería la elección definitiva, pero Bonavía ordenó a del Valle que citara a los electores de la segunda elección y en lugar de Porras se nombrara otro elector y se eligiera ayuntamiento, en realidad era la tercera anulación de elecciones. También le ordenó que si se observaban visos de inquietud que llevara a disturbios pusiera nuevamente al antiguo ayuntamiento en funciones. El 30 de abril, antes de empezar la cuarta elección, Trespalacios leyó una carta realzando los aspectos constitucionales de igualdad ante la ley y lanzó la acusación de que los intereses generales se supeditaban a una familia, refiriéndose a Valois e Irigoyen. Para evitar más disputas pasó a una propuesta muy radical que iba más allá de la Constitución: que todas las personas que se consideraran aptas e idóneas para desempeñar los cargos del ayuntamiento se sortearan para ocupar los puestos de cabildo. Todos votaron en contra de la propuesta de Trespalacios, pero es significativo que lo apoyaba Mateo Sánchez Álvarez que también había sido implicado en la conspiración de 1811. Se procedió a la elección y Trespalacios, en esta ocasión, no fue electo a puesto alguno de cabildo (АHмCH, Fondo: Colonia, Sección: Gobierno, Caja 48, Exp. 35). A continuación, hizo una serie de impugnaciones y pidió se declarara nula la elección pero fueron desestimados sus pronunciamientos. Trespalacios protestó ante Bonavía haciendo una serie de observaciones sobre la elección de Irigoyen, no se especifica la naturaleza de las mismas, pero también impugnó la elección de Jáuregui pidiendo la anulación de diputados a Cortes argumentando que se había actuado con parcialidad. Sobre el primer aspecto Bonavía le respondió que la elección de Irigoyen se apoyaba en los derechos que tenía de ciudadano, sobre el segundo le dijo 
que el acta estaba apegada en todo a la Constitución. Además, Trespalacios había recibido del propio Bonavía una reprimenda sobre su "conducta" lo que lastimaba cada vez más su honor y lo radicalizaba ya que decía que se había actuado en todo a favor de "cierto partido" es decir de los peninsulares (AGN, Infidencias 67, ff. 5-8). Junto con Mariano Herrera, Juan Pablo Caballero y José María Arrieta va a iniciar una conspiración, pero delatado por el último, será apresado y desterrado de las Provincias Internas.

\section{Cuadro 1}

\begin{tabular}{|c|c|c|c|c|}
\hline \multicolumn{5}{|c|}{ Cargo y fecha de elección de ayuntamiento constitucional } \\
\hline Cargo & $\begin{array}{l}8 \text { de diciembre } \\
\text { de } 1813\end{array}$ & $\begin{array}{l}16 \text { de enero de } \\
1814\end{array}$ & $\begin{array}{l}2 \text { de abril de } \\
1814\end{array}$ & $\begin{array}{l}30 \text { de abril de } \\
1814\end{array}$ \\
\hline $\begin{array}{l}\text { Alcalde } \\
1 .^{\circ}\end{array}$ & $\begin{array}{l}\text { Francisco José } \\
\text { de Jáuregui }\end{array}$ & $\begin{array}{l}\text { Francisco José } \\
\text { de Jáuregui }\end{array}$ & Pedro Valois & Pedro Valois \\
\hline $\begin{array}{l}\text { Alcalde } \\
2 .^{\circ}\end{array}$ & Pedro Valois & $\begin{array}{l}\text { José Feliz Tres- } \\
\text { palacios }\end{array}$ & Rafael Zubía & Rafael Zubía \\
\hline \multirow[t]{8}{*}{ Regidores } & $\begin{array}{l}\text { Simón de } \\
\text { Ochoa }\end{array}$ & $\begin{array}{l}\text { Simón de } \\
\text { Ochoa }\end{array}$ & $\begin{array}{l}\text { Simón de } \\
\text { Ochoa }\end{array}$ & $\begin{array}{l}\text { Simón de } \\
\text { Ochoa }\end{array}$ \\
\hline & Rafael Zubía & Rafael Zubía & $\begin{array}{l}\text { José Francisco } \\
\text { Galindo }\end{array}$ & $\begin{array}{l}\text { José Francisco } \\
\text { Galindo }\end{array}$ \\
\hline & $\begin{array}{l}\text { Pedro Ignacio } \\
\text { de Irigoyen }\end{array}$ & $\begin{array}{l}\text { Pedro Ignacio } \\
\text { de Irigoyen }\end{array}$ & $\begin{array}{l}\text { Pedro Ignacio } \\
\text { de Irigoyen }\end{array}$ & $\begin{array}{l}\text { Pedro Ignacio } \\
\text { de Irigoyen }\end{array}$ \\
\hline & $\begin{array}{l}\text { Juan de Elgue- } \\
\text { zabal }\end{array}$ & $\begin{array}{l}\text { Juan de Elgue- } \\
\text { zabal }\end{array}$ & $\begin{array}{l}\text { Juan de Elgue- } \\
\text { zabal }\end{array}$ & $\begin{array}{l}\text { Juan de Elgue- } \\
\text { zabal }\end{array}$ \\
\hline & $\begin{array}{l}\text { José Feliz Tres- } \\
\text { palacios }\end{array}$ & Salvador Porras & $\begin{array}{l}\text { José Feliz Tres- } \\
\text { palacios }\end{array}$ & $\begin{array}{l}\text { José María Po- } \\
\text { rras }\end{array}$ \\
\hline & $\begin{array}{l}\text { Joaquín Mari- } \\
\text { chalar }\end{array}$ & $\begin{array}{l}\text { Francisco Ga- } \\
\text { lindo }\end{array}$ & $\begin{array}{l}\text { Joaquín Mari- } \\
\text { chalar }\end{array}$ & $\begin{array}{l}\text { Joaquín Mari- } \\
\text { chalar }\end{array}$ \\
\hline & $\begin{array}{l}\text { Mariano Orca- } \\
\text { sitas }\end{array}$ & $\begin{array}{l}\text { Mariano Orca- } \\
\text { sitas }\end{array}$ & $\begin{array}{l}\text { Mariano Orca- } \\
\text { sitas }\end{array}$ & $\begin{array}{l}\text { Mariano Orca- } \\
\text { sitas }\end{array}$ \\
\hline & Eugenio Vizoso & Eugenio Vizoso & Eugenio Vizoso & Eugenio Vizoso \\
\hline \multirow[t]{2}{*}{ Síndicos } & $\begin{array}{l}\text { Justo Pastor de } \\
\text { Madariaga }\end{array}$ & $\begin{array}{l}\text { Sabino Diego } \\
\text { de la Pedrueza }\end{array}$ & $\begin{array}{l}\text { Justo Pastor de } \\
\text { Madariaga }\end{array}$ & $\begin{array}{l}\text { Justo Pastor de } \\
\text { Madariaga }\end{array}$ \\
\hline & $\begin{array}{l}\text { José María Ruiz } \\
\text { de Bustamante }\end{array}$ & $\begin{array}{l}\text { José María Ruiz } \\
\text { de Bustamante }\end{array}$ & $\begin{array}{l}\text { José María Ruiz } \\
\text { de Bustamante }\end{array}$ & $\begin{array}{l}\text { José María Ruiz } \\
\text { de Bustamante }\end{array}$ \\
\hline
\end{tabular}

Fuente: AHMCH, Fondo: Colonia, Sección: Gobierno, Caja 48, Exp. 35. 


\section{CONCLUSIONES}

El conflicto surgido en las elecciones de ayuntamiento constitucional, de diputados a Cortes y provinciales en la villa de Chihuahua pone de manifiesto diferencias y rivalidades entre criollos y españoles en conflicto por acceder y ocupar los espacios de poder abiertos por los procesos electorales. No hay pues una competencia entre candidatos, no hay una contienda por programas o banderas políticas, no hay ideologías que exponer o defender. Se trataba de elegir en torno a las cualidades no a las ideas. Primaban en esas características el honor y el modo honesto de vivir. Precisamente Trespalacios centraba su descontento en cuestiones de honor al verse relegado por los españoles. Los electores van a elegir representantes que si bien en primer término defienden sus intereses también redunda en el bien de la comunidad.

Las elecciones no cambiaron la composición del reducido círculo de poder que tenía en el ayuntamiento su principal espacio político. El ayuntamiento constitucional y los cargos de diputados siguieron siendo ocupados por ellos. Se trataba de elegir a los más capaces según las formas, expresiones y figuras del momento. Herrera expresó que el pueblo quería ayuntamiento constitucional y no aristocracia, pero ese pueblo no tenía otra opción.

Las anulaciones de las elecciones de ayuntamiento constitucional no son por fraude ni por la disputa por concepciones políticas diferentes, sino por procedimiento. Las autoridades provinciales se mostraron muy rigurosas en la observancia de los procedimientos electorales. En la primera elección la omisión en el nombramiento, no era electo, por la junta ciudadana llevó a la primera anulación. La Constitución estableció la facultad de poder privar o suspender de la ciudadanía a los sujetos en nombre de la conveniencia pública y la estabilidad social. El artículo 24 fijaba que la calidad de ciudadano se suspende, entre otros aspectos, por hallarse procesado criminalmente, en ese sentido Porras no podía participar en los comicios, pero el cuestionamiento era si solo quitarlo del cargo del que había sido electo o nulificar toda la elección. Esa parece haber sido en parte la recapacitación del comandante general que 
después de haber anulado la elección ordena se repongan los electores y se nombre otro en lugar de Porras.

Los miembros del ayuntamiento estaban sumamente inconformes con las intervenciones de las autoridades provinciales, lo cual paradójicamente les había restado autonomía, ya que antes era un proceso local, pero la reglamentación constitucional les daba la facultad de convocar y organizar las elecciones que en este caso era por medio del subdelegado político. Por otro lado, tenemos a una élite ilustrada que conocían la Constitución y su reglamentación y al momento de discutir internamente o con las autoridades provinciales la utilizan. La Constitución crea un marco discursivo común en el cual se está expresando tanto la aceptación como la disidencia. Se han abierto canales de expresión no solo para los criollos, sino también para los españoles a través de los cuales reclaman una mayor participación y equidad con el virreinato y con la misma metrópoli.

Tenemos un ciudadano que es esencialmente un votante, la oligarquía local al defenderse de las intromisiones de las autoridades provinciales autorizaron a los electores a defender los derechos del pueblo, ese era el asunto no hablaban de ciudadanos, sino de los sujetos no ilustrados pero que habían alcanzado derechos de ciudadanía a los cuales no los consideraban sus iguales. Había entonces una ciudadanía aristócrata que era la que tenía acceso a ser electa y una ciudadanía del pueblo votante, pero en los dos casos hablamos de protociudadanía.

La Constitución al nombrar a ciertos sectores de la sociedad ciudadanos no los convierte de facto en lo que pretende que sea un ciudadano. Es una ruptura radical con las formas tradicionales del vecino así que los procedimientos constitucionales se siguen alimentando de las formas preconstitucionales. Debe haber un proceso largo y de arduo trabajo para lograr la interiorización social cultural de lo que se pretende sean los usos de la ciudadanía, es por eso que los sujetos, en esa etapa, son protociudadanos. 


\section{FUENTES}

\section{Archivos}

AGN, Archivo General de la Nación

AHMCH, Archivo Histórico Municipal de Chihuahua

\section{Bibliografía}

Almada, Francisco R. Diccionario de historia, geografía y biografía chihuahuenses. Chihuahua: Universidad Autónoma de Chihuahua, 1968.

Annino, Antonio, “Ciudadanía 'versus' gobernabilidad republicana en México", en, Hilda Sabato (coordinadora), Ciudadanía política y formación de las naciones. Perspectivas históricas de América Latina. México: FCE / El Colegio de México, 1999, pp. 62-93.

Annino, Antonio, "Cádiz y la revolución territorial de los pueblos mexicanos, 1812-1821," en Antonio Annino (coordinador), Historia de la elecciones en Iberoamérica, siglo XIX. México: FCE, 1995, pp. 177-226.

Arroyo García, Israel, La arquitectura del estado mexicano: formas de gobierno, representación y ciudadanía, 1821-1857, México, Instituto Mora, BUAP, 2011.

Weber, David J. La frontera norte de México, 1821-1846. El sudoeste norteamericano en su época mexicana. México: FCE, 1988.

Benson, Nettie Lee, La diputación provincial y el federalismo mexicano. México: El Colegio de México-UnAM, 1994.

Chust, Manuel e Ivana Frasquet, "Soberanía hispana, soberanía mexicana: México, 1810-1824”, en Manuel Chust (coordinador). Doceañismos, constituciones e independencias. La constitución de 1812 y América. Madrid: Fundación Mapfre, 2006, pp. 169-236.

Cruzado Campos, Carlos Gabriel, Diputados novohispanos en las Cortes de Madrid, 1820-1824. La experiencia política y su influencia en la construcción del nuevo estado. UNAM, 2013, tesis de doctorado.

Domínguez Rascón, Alonso, Estado, frontera y ciudadanía: el septentrión entre el antiguo régimen y la formación de la nación mexicana. Leiden, Holanda, 2013, tesis de doctorado.

Escobar Ohmstede, Antonio, "Instancias y órganos políticos en la transición del siglo XVIII al XIX. Las Huastecas." en: Moisés Guzmán Pérez (Coord.), Cabildos, repúblicas, y ayuntamientos constitucionales en la inde- 
pendencia de México. Morelia: Universidad Michoacana de San Nicolás de Hidalgo / Congreso del estado de Michoacán, 2009, pp. 63-92.

Gallegos, Enrique G., "Del sujeto abstracto al ciudadano: apertura y clausura de la ciudadanía en la modernidad," en Polis, Vol. 7, Núm. 2, 2011. González, Judith, "Documentos de la Independencia en la Nueva Vizcaya”, en Textos de la Nueva Vizcaya, Chihuahua: uAcj, Año 1, Núm. 2, 1993, pp. 1-83.

Gortari Rabiela, Hira de, "Representación y sistema electoral de Cádiz al 1. 'Federalismo: San Luis Potosí y el Distrito Federal”, en Víctor Gayol (Coord.), Formas de gobierno en México. Poder político y actores sociales a través del tiempo, Vol. II. Zamora: El Colegio de Michoacán, 2012, pp. 351-380.

Guerra, François-Xavier, "El soberano y su reino. Reflexiones sobre la génesis del ciudadano en América Latina", en Hilda Sabato (Coord.), Ciudadanía política y formación de las naciones. Perspectivas históricas de América Latina. México: FCE/El Colegio de México, 1999: 57, pp. 33-61.

Guzmán, Martín Luis, México en las Cortes de Cádiz. México: Empresas Editoriales, 1949.

Guzmán Pérez, Moisés (coord.), "Presentación”, en Cabildos, repúblicas, y ayuntamientos constitucionales en la Independencia de México. Morelia: Universidad Michoacana de San Nicolás de Hidalgo / Congreso del estado de Michoacán, Michoacán, 2009, pp. 7-14.

Hernández Chávez, Alicia, La tradición republicana del buen gobierno. MéxiCO: FCE/El Colegio de México, 1993.

Hernández, María del Pilar, "El concepto de nación y ciudadano en la constitución de Cádiz", en Daniel Barceló Rojas y José Serna de la Garza (coords.), Memoria del seminario internacional: conmemoración del bicentenario de la constitución de Cádiz. Las ideas constitucionales de América Latina. México, UNAm, Senado de la República, 2013.

Marshall, T. H., Tom Bottomore, Ciudadanía y clase social, México, Alianza Editorial, 1998.

Nelen, Yvette. De Illustere Heren van San Pablo (Los señores ilustres de San Pablo, gobierno local en el siglo XIX), capítulo 2. Tesis de doctorado, Universidad de Leiden, 1999.

Orozco Orozco, Víctor, El estado de Chihuahua en el parto de la nación, 1810-1831. México: El Colegio de Chihuahua/Ichicult/UAcj/Plaza y Valdés, 2007. 
Pietschmann, Horst, Las reformas borbónicas y el sistema de intendencias de Nueva España. Un estudio político administrativo. México: FCE, 1996.

Recopilación de las Leyes de los Reynos de las Indias. Archivo Digital de la Legislación en el Perú. http://www.congreso.gob. pe/ntley/LeyIndiaP. htm

Sabato, Hilda, “Introducción”, en Hilda Sabato (Coord.), Ciudadanía política y formación de las naciones. Perspectivas históricas de América Latina. México: FCE/El Colegio de México, 1999, pp. 11-29.

Sánchez Montiel, Juan Carlos, "Reordenamiento del gobierno local e implantación de un Nuevo Sistema de representación política: San Luis Potosí, 1812-1821”, en Moisés Guzmán Pérez (Coord.), Cabildos, repúblicas, y ayuntamientos constitucionales en la Independencia de México. Morelia: Universidad Michoacana de San Nicolás de Hidalgo/Congreso del estado de Michoacán, 2009, pp. 301-331.

Talavera Ibarra, Oziel Ulises. "El nacimiento del ayuntamiento de Uruapan o el fin del pueblo de indios de San Francisco Uruapan”, en Moisés Guzmán Pérez (Coord.). Cabildos, repúblicas, y ayuntamientos constitucionales en la Independencia de México. Morelia: Universidad Michoacana de San Nicolás de Hidalgo/Congreso del estado de Michoacán, 2009: 120. También Escobar, 2009.

Tateishi, Hirotaka. "La Constitución de Cádiz de 1812 y los conceptos de Nación/Ciudadano". Hitotsubashi University, Mediterranean world, 2008. http://tufs.academia.edu/HirotakaTateishi

Vaquera, Richard, Paso del Norte: Regional center, 1813-1821. El Paso: UTEP, 1974.

J. Weber, David, La frontera norte de México, 1821-1846. El sudoeste norteamericano en su época mexicana. México: FCE, 1988. 